Agro-Science Journal of Tropical Agriculture, Food, Environment and Extension Volume 11 Number 3 September 2012 pp 27 - 37

ISSN IIIY-7455

\title{
MULTI-LOCATION EVALUATION OF YIELD AND YIELD COMPONENTS OF GRAIN COWPEA (Vigna unguiculata (L.) Walp.) GROWN IN SOUTHEASTERN NIGERIA
}

\author{
Ezeaku, I.E., Mbah, B.N. and Baiyeri, K.P \\ Department of Crop Science, University of Nigeria, Nsukka, Nigeria \\ Corresponding author paul.baiyeri@unn.edu.ng
}

\begin{abstract}
An evaluation study was carried out on 14 cowpea genotypes grown across four locations representing different environments in southeastern Nigeria, namely, Umudike, Nsukka, Igbariam and Abakaliki. Differences among genotypes, locations and genotypes by location components of variation were highly significant $(P<0.05)$ for all the traits studied. Cowpea genotype, IT98K-131-2 produced significantly higher grain yield in Umudike and Igbariam, and ranked second and third respectively, in Abakaliki and Nsukka locations. Genotypes IT84S-2246-4 and IT97K-1069-6 were the highest grain yielders in Abakaliki and Nsukka respectively, indicating specific adaptation. Analysis of variance and GGE biplot both revealed that IT98K-131-2 exhibited superior performance across the four testing environments. Most of the yield component traits such as number of pods per plant, 100 seed weight, pod weight, pod length, seed weight and grain yield were best expressed in Umudike while Abakaliki supported the highest expression of growth and reproductive traits. No trait was particularly best expressed in Igbariam and Nsukka locations except dry fodder weight that was well expressed in Igbariam. Umudike and Abakaliki locations were found to significantly support higher cowpea grain yield than the other two locations. The local variety, IT89KD-288, IT1069-6, IT90K-568-1 and IT98K-131-2 constituted the vertex genotypes within the biplot model, indicating that the five genotypes were genetically divergent from each other with respect to the traits assessed. Similarly, the four locations individually occupied the vertices of the biplot polygon indicating that they are inherently different from each other justifying their use for this study. The local variety and IT89KD-288 (an improved photosensitive long duration genotype) gave significantly higher dry and fresh fodder weight and took longer time to bloom and attain maturity. However, the two genotypes performed significantly poorer for grain yield in all the locations suggesting that they are purely fodder type cowpea. Brown seeded cowpea genotypes out yielded the white seeded in all the locations of the study revealing that cowpea with brown seed coat color are better adapted to southeastern Nigeria than white seeded genotypes.
\end{abstract}

Key words: Grain cowpea, genotypes, yield component, multi-location, evaluation

\section{INTRODUCTION}

World cowpea production in 1997 was estimated at 3 million tones from 12.5 million hectares with Nigeria accounting for 1.7 million tones from 4 million hectares (Singh et al., 1997). Cowpea is an important food legume and a versatile crop extensively grown for several purposes. It provides nutritious food for man as well as fodder resource for livestock (Tarawali et al., 1997). Cowpea seed is valued for its high protein content which varies between 23-30 percent and other essential nutrients like carbohydrate, vitamins A and thiamin, (Suzanna and Singh, 1987). Cowpea has the unique ability to fix atmospheric nitrogen into the soil through symbiosis with rhizobium in the root nodules thereby improving soil fertility. It is also useful as green manure; the leafy prostrate cultivars provide ground cover, thus suppressing weeds and providing protection against soil erosion. In West Africa, a substantial part of the cowpea production comes from the drier regions of northern Nigeria (Singh et al., 1997). Southeastern region although has favorable weather and soil that can sustain commercial production, it unfortunately accounted for only about $0.57 \%$ of the total cowpea production and $0.38 \%$ of the total area cultivated in Nigeria in 2007 (APS, 2008). The low level of productivity is due mainly to use of landraces owing to none availability of suitably adapted improved high yielding genotypes. Consequently, due to low yield of the landraces most of the cowpea seeds 
consumed in southeastern Nigeria continued to be brought in from the northern part of the country. However, as advances are made in crop improvement targeting none traditional cowpea growing regions, there is an opportunity for commercial production of the crop in longer season, wetter agro-ecologies (Quin 1997). In order to identify high yielding cowpea genotypes suitable to southeastern region, it is necessary that multi-location evaluation of large number of diverse improved cowpea genotypes be carried out within the different agro-ecologies of the region. Multi-environment evaluation trials of crop cultivars are essential in view of the apparent inconsistencies in the performance of genotypes across different environments (Ezeaku 2013).

The phenology of cowpea has been identified as one of the important physiological factors determining adaptation of crop species to various agro-ecological zones, and equally determines yield differences among cowpea genotypes (Summerfield et al., 1985). Ntare (1992) in his studies on the performance of cowpea genotypes across different environmental conditions found a considerable variation in performance among cultivars for reproductive, growth and yield components. However, a greater understanding is needed not only of the environmental factors that interact with the genotype to influence crop reproductive development and yield but also of the interaction between genotype and environment factors which control these traits (Baiyeri, 1998). This endeavor will help not only to identify superior genotypes but also appropriate locations and traits best expressed in each environment with the overall aim of solving the problem of low cowpea yield in southeast region.

Although International Institute of Tropical Agriculture (IITA), Ibadan, Nigeria and its partners have developed cowpea varieties with high grain yield potential and disease/pest resistance, not much multi-environment trials have been carried out in southeastern Nigeria with a view to determine their relative performance (Singh, B.B., personal communication). This study was undertaken to evaluate 14 diverse cowpea genotypes across four different locations in southeastern Nigeria in other to identify the environment most suitable for cowpea productivity and select best yielding genotype(s) in each environment.

\section{MATERIALS AND METHODS}

The experiment was conducted in four locations selected to fairly represent the different agroecologies of southeastern Nigeria. At Nsukka the experiment was conducted at the Department of Crop Science, Faculty of Agriculture Teaching and Research Farm, University of Nigeria; in Umudike it was conducted at the Experimental Farm of National Root Crop Research Institute; in Igbariam it was carried out at the Anambra State College of Agriculture Training Farm, Igbariam while in Abakaliki it was conducted at the Faculty of Agriculture Research Farm of Ebonyi State University, Abakaliki. Across the four locations the experiment was established during the first and second week in August of 2006. The weather and some soil variables of the experimental sites are presented in Table 1.

The fourteen cowpea genotypes consisting of 13 improved and a local check were used for the study. The treatments were laid out in a randomized complete block design (RCBD), replicated four times on four rows of 4 $\mathrm{m}$ long per plot with a total number of 56 plots. The 14 genotypes consists of seed size that ranged from large to medium with seven genotypes possessing brown seed coat color while the remaining seven possessed white seed coat color.

Seed texture ranged from smooth to rough with two out of the 14 genotypes classified as photosensitive while the remaining 12 genotypes are classified as photo-insensitive.

The experimental plot was ploughed, harrowed and ridged. Prior to ridging a basal dose of $100 \mathrm{~kg}$ NPK $15-15-15$ per hectare plus $1000 \mathrm{~kg}$ per hectare of well cured cow dung was broadcasted uniformly and latter incorporated into the soil and ridges made thereafter. Inter row spacing was $75 \mathrm{~cm}$ while intra row spacing was $20 \mathrm{~cm}$ with $2-3$ seeds per hill at $3-5 \mathrm{~cm}$ depth. Each plot consisted of four rows of four meter long while net plot was the inner two rows $(1.5 \mathrm{x}$ $4 \mathrm{~m})$ made up of about 84 plants. Plants were thinned to two stands per hill two weeks after crop emergence. The crop was protected against insect pests by application of $100 \mathrm{ml}$ of insecticide, cypermethrin and dimethoate mixture containing $30 \mathrm{~g}$ and $250 \mathrm{~g}$ active ingredients respectively. The insecticides were applied using 15 litres knapsack sprayer. Weeds were manually controlled as regularly as they appeared while other agronomic practices were observed.

Field data were collected from the inner two rows in each replication. Destructive sampling was done using the outer two rows (guard rows). Observations were recorded on 16 different variables consisting of seven growth, three reproductive and six grain yield components. The variables are, number of plants in two center rows (net plot), days to $50 \%$ first flower, days to maturity, pod weight, seed weight, fresh fodder weight, dry fodder weight, 100-seed weight, number of pods per plant, number of nodules, pod length, number of pod per plant, number of 
seed

Ezeaku, I.E., Mbah, B.N. and Baiyeri, K.P

of taproot.

Data was subjected to analysis of variance (ANOVA) following the GENSTAT, 2003 procedures outlined for RCBD. Significant differences among treatment means was compared using F-LSD while means of genotype by location for grain yield and dry fodder yield, genotype by traits and location by traits was computed using GGE biplot.

\section{RESULTS}

The genotype IT89KD-288 produced significantly $(\mathrm{p}<0.05)$ higher mean dry fodder weight than the rest treatments, while genotype IT90K-568-1 produced significantly lowest dry fodder weight (Table 2). However, local check produced statistically similar dry fodder weight with IT89K-288 both of which are long duration photosensitive cowpea biotypes. Igbariam location supported significantly higher mean dry fodder weight than the other locations while Nsukka location produced the least. In particular, local check produced significantly higher dry fodder weight in Umudike location while it produced the least in Nsukka followed by Abakaliki.

Table 3 showed that IT89KD-288 produced significantly higher mean vine length but did not differ significantly with IT81D-994 and local genotypes indicating that long duration photosensitive genotypes produced higher dry matter in terms of higher mean dry fodder weight

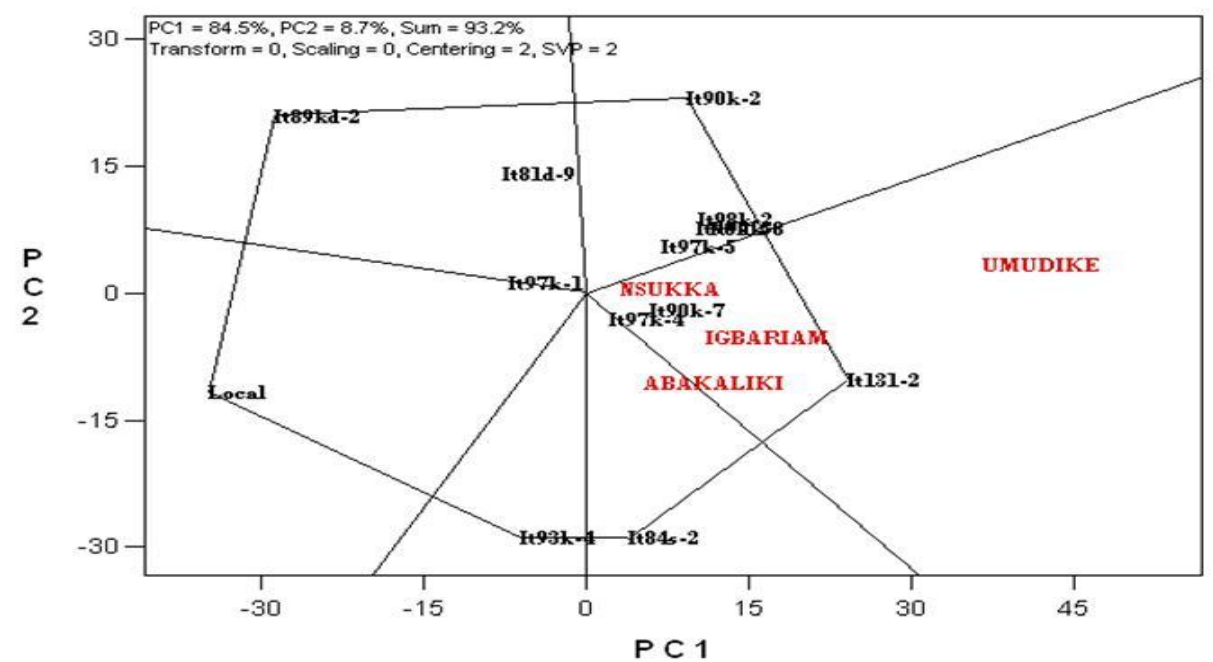

Figure 1: Biplot of genotype by location (GL) for grain yield per hectare

IT97K-556-4= it97k-5; IT97K-499-35= it97k-4; IT98K-205-8= it98k-2; IT84S-2246-4=it84s-2; IT93K-452-1= it93k4; IT97K-1069-6= it97k-1; IT90K-76= it90k-7; IT81D-994= it81d-9; IT98K-131-2= it131-2; IT90K-82-2= it90k-8; IT90K-568-1= it90k-5; IT89KD-288= it89kd-2; IT90K-277-2= it90k-2

Table 1: Total rainfall, mean temperature, latitude, longitude, elevation and some soil characteristics of the four locations used for the study

\begin{tabular}{|c|c|c|c|c|}
\hline \multirow[t]{2}{*}{ Weather and soil variables } & \multicolumn{4}{|c|}{ LOCATION } \\
\hline & Umudike & Nsukka & Igbariam & Abakaliki \\
\hline Total rainfall $(\mathrm{mm})$ & 2700 & 2000 & 1900 & 2000 \\
\hline Mean temperature $\left({ }^{\circ} \mathrm{C}\right)$ & 31 & 28 & 28 & 35 \\
\hline Latitude & $05^{0} 29^{\prime} \mathrm{N}$ & $06^{0} 51^{\prime} \mathrm{N}$ & $06^{0} 57^{\prime} \mathrm{N}$ & $06^{0} 19^{\prime} \mathrm{N}$ \\
\hline Longitude & $07^{0} 35^{\prime} \mathrm{E}$ & $07^{0} 29^{\prime} \mathrm{E}$ & $06^{0} 20^{\prime} \mathrm{E}$ & $08^{0} 70^{\prime} \mathrm{E}$ \\
\hline Elevation (m) & 122 & 400 & 160 & 447 \\
\hline Soil Textual Class & Sandy Loam & Sandy Loam & Sandy Clay Loam & Sandy Clay Loam \\
\hline Clay $(\%)$ & 14 & 33 & 42 & 39 \\
\hline Coarse Sand $(\%)$ & 27 & 42 & 20 & 26 \\
\hline Organic Carbon (\%) & 1.2 & 0.8 & 0.8 & 0.6 \\
\hline Organic Matter & 1.9 & 1.4 & 1.3 & 1.8 \\
\hline Soil $\mathrm{p}^{\mathrm{H}}$ & 4.5 & 4.0 & 5.6 & 5.1 \\
\hline CEC & 9.0 & 3.9 & 13 & 12.5 \\
\hline Base Saturation (\%) & 14.2 & 35.1 & 19.1 & 67.2 \\
\hline
\end{tabular}




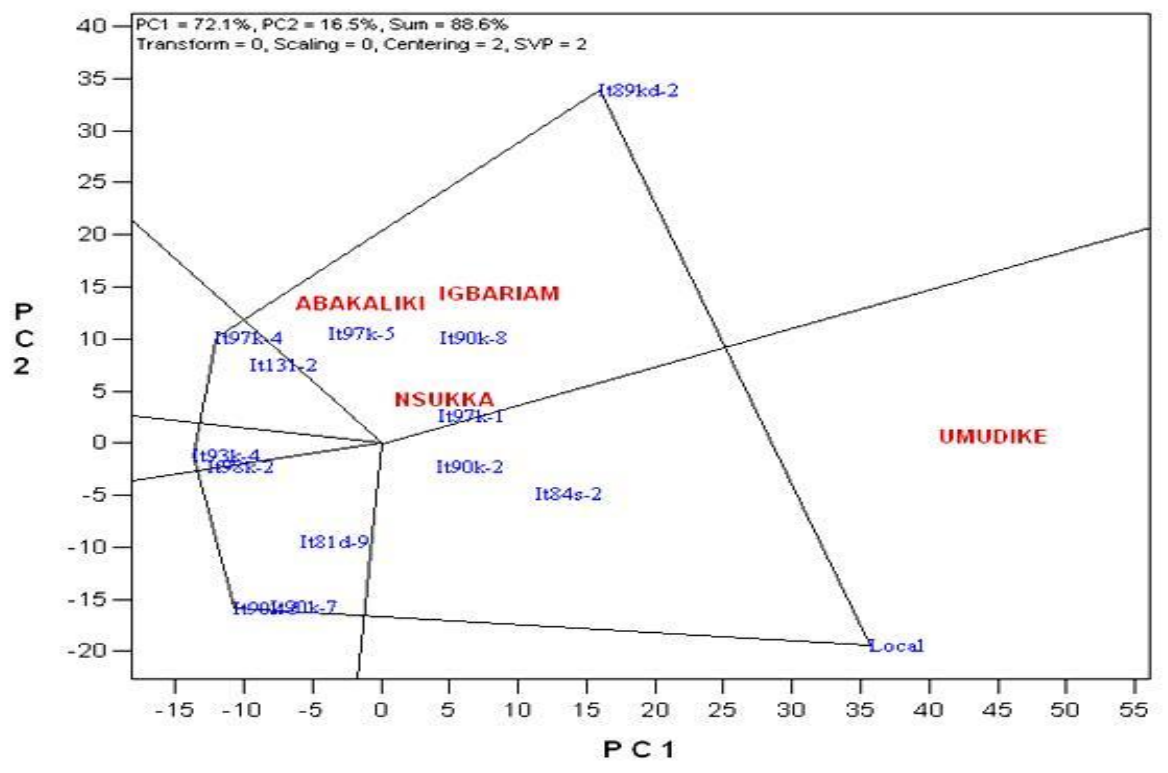

Figure 2: Biplot of genotype by location (GL) for dry fodder yield

IT97K-556-4= it97k-5; IT97K-499-35= it97k-4; IT98K-205-8= it98k-2; IT84S-2246-4=it84s-2; IT93K-452-1= it93k4; IT97K-1069-6= it97k-1; IT90K-76= it90k-7; IT81D-994= it81d-9; IT98K-131-2= it131-2; IT90K-82-2= it90k-8; IT90K-568-1= it90k-5; IT89KD-288= it89kd-2; IT90K-277-2= it90k-2

Table 2: Effect of location and genotype on dry fodder weight (kg)

\begin{tabular}{|c|c|c|c|c|c|}
\hline \multirow[t]{2}{*}{ GENOTYPE } & \multicolumn{5}{|c|}{\begin{tabular}{|l} 
LOCATION \\
\end{tabular}} \\
\hline & Umudike & Nsukka & Igbariam & Abakaliki & Mean \\
\hline IT 97K-556-4 & 986.00 & 141.14 & 1502.00 & 1170.22 & 949.84 \\
\hline IT 97K-499-35 & 687.45 & 185.25 & 1306.14 & 1365.00 & 885.96 \\
\hline IT 98K-205-8 & 594.02 & 169.00 & 1356.40 & 950.65 & 767.52 \\
\hline IT 84S-2246-4 & 1594.44 & 229.00 & 1327.00 & 858.32 & 1002.19 \\
\hline IT 93K-452-1 & 680.00 & 38.45 & 932.00 & 1475.17 & 781.41 \\
\hline IT 97K-1069-6 & 1358.11 & 531.33 & 1146.10 & 1188.00 & 1055.89 \\
\hline IT 90K-76 & 792.50 & 135.29 & 1132.22 & 798.40 & 714.60 \\
\hline IT 81D-994 & 906.17 & 156.15 & 114.70 & 957.000 & 791.51 \\
\hline IT 98K-131-2 & 756.00 & 163.00 & 1426.31 & 1165.53 & 877.71 \\
\hline IT 90K-82-2 & 1348.00 & 132.00 & 1435.43 & 1223.00 & 1034.61 \\
\hline IT 90K-568-1 & 681.15 & 180.63 & 1116.28 & 800.00 & 694.52 \\
\hline IT 89KD-288 & 1788.34 & 375.80 & 1927.00 & 1313.10 & 1351.06 \\
\hline IT 90K-277-2 & 1338.00 & 433.26 & 1132.11 & 1087.37 & 997.69 \\
\hline Local & 2613.00 & 9.00 & 1153.00 & 647.00 & 1105.50 \\
\hline Mean & 1151.66 & 205.66 & 1288.48 & 1071.38 & \\
\hline
\end{tabular}

F-LSD (P=0.05)

Location $(\mathrm{L})=117.7$

Genotype $(G)=220.3$

$\mathrm{L} \times \mathrm{G}=440.3$

and longer vines. Abakaliki location supported significantly longer vines which did not differ significantly with vine length produced in Umudike location. Nsukka location however supported significantly lower vine length than the rest locations.

The genotype IT98K-131-2 produced significantly higher mean grain yield than the rest genotypes while IT89KD-288 produced significantly lower mean grain yield which did not differ significantly with local genotype (Table 4), indicating that IT89KD-288 and local are purely fodder type cowpea. Umudike location supported significantly higher overall mean grain yield than the rest locations except in
Abakaliki where the mean grain yield did not differ significantly with that of Umudike location. Conversely, Nsukka location produced significantly lower grain yield than the rest locations but statistically similar with Igbariam. Genotype by environment interaction shows that IT98K-131-2 produced significantly higher mean grain yield in Umudike and Igbariam while it ranked second and third in Abakaliki and Nsukka respectively but its mean grain yield did not differ significantly with the highest grain yielders in those two locations. The two genotypes that displayed location specific adaptation include IT84S-2246-4 with highest mean grain yield in Abakaliki and IT84S-2246-4 
th:

Ezeaku, I.E., Mbah, B.N. and Baiyeri, K.P

Nsukka.

The mean 100 seed weight was significantly higher in genotype IT97K-556-4 which is comparable with that expressed by IT90K-2772, IT89KD-288 and IT81D-994 (Table 5). The local check produced significantly lower mean 100 seed weight in all the locations except in Umudike where the mean 100 seed weight by local did not differ significantly with the genotype that produced the highest mean 100 seed weight. The mean 100 seed weight in Igbariam is significantly higher than that at the other locations. The trait is significantly higher in Umudike than that at Nsukka. Among all the improved genotypes, IT84S-2246-4 and IT90K82-2 produced significantly lower mean 100 seed weight across all the locations.

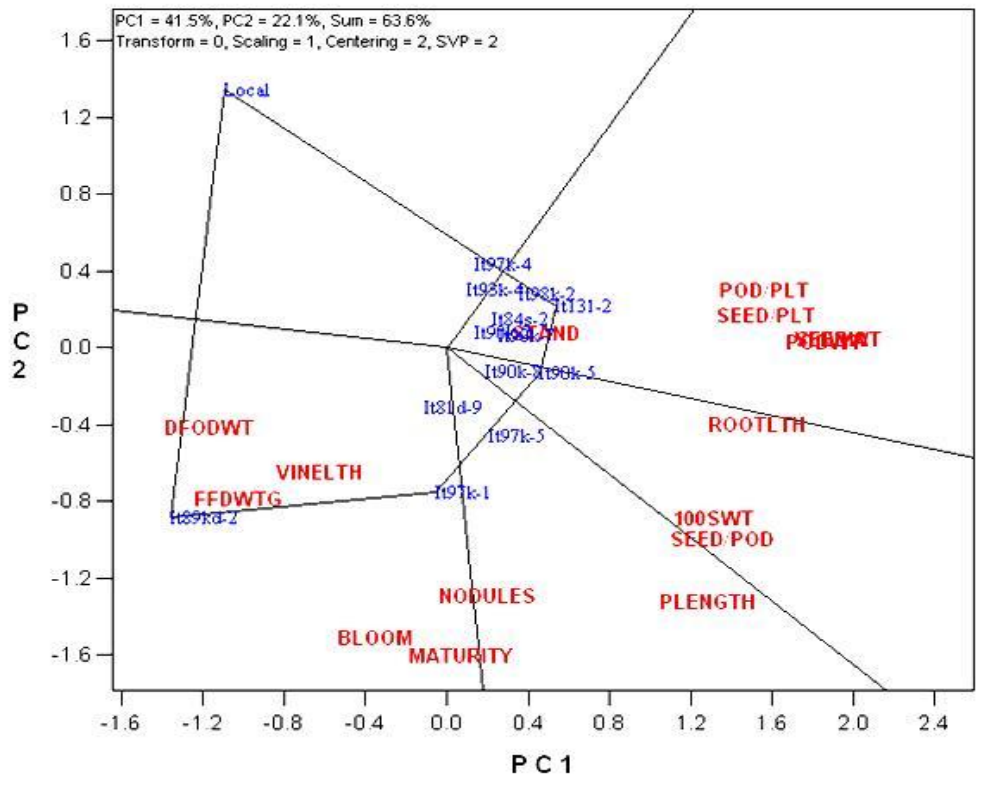

Figure 3: Biplot of genotype by traits (GT)

BLOOM = Days to 50 percent flowering; MATURITY = Days to maturity; $100 \mathrm{SWT}=100$ Seed weight POD/PLT $=$ Number of pods per plant; SEED /POD = Number of seeds per pod; SEED/PLT= Number of seeds per plant; PLENGTH = Pod length; PODWT = Pod weight; SEEDWT = Seed weight; GYLD/HA = Grain yield per hectare; DFWT = Dry fodder weight; FFWT = Fresh fodder weight; NODULES=Number of nodules; NSTAND=Number of plant stand; ROOTLTH=Root length; VINELTH=Vine length

Table 3: Effect of location and genotype on vine length $(\mathrm{cm})$

\begin{tabular}{lrrrrr}
\hline & \multicolumn{5}{c}{ LOCATION } \\
\cline { 2 - 5 } GENOTYPE & Umudike & Nsukka & Igbariam & Abakaliki & Mean \\
\hline IT 97K-556-4 & 92.25 & 34.00 & 87.07 & 104.07 & 79.35 \\
IT 97K-499-35 & 101.13 & 22.31 & 96.00 & 119.00 & 84.61 \\
IT 98K-205-8 & 86.11 & 33.00 & 105.00 & 166.17 & 97.57 \\
IT 84S-2246-4 & 101.00 & 28.65 & 96.30 & 89.43 & 78.85 \\
IT 93K-452-1 & 122.00 & 28.20 & 117.42 & 153.27 & 105.22 \\
IT 97K-1069-6 & 185.21 & 55.18 & 180.09 & 146.11 & 141.65 \\
IT 90K-76 & 125.74 & 22.42 & 119.00 & 102.03 & 92.30 \\
IT 81D-994 & 213.40 & 32.60 & 208.13 & 208.01 & 165.54 \\
IT 98K-131-2 & 92.93 & 42.00 & 88.01 & 132.00 & 88.74 \\
IT 90K-82-2 & 92.00 & 23.33 & 88.91 & 125.42 & 82.42 \\
IT 90K-568-1 & 148.32 & 22.76 & 167.00 & 138.08 & 119.04 \\
IT 89KD-288 & 241.00 & 128.03 & 155.00 & 130.00 & 175.79 \\
IT 90K-277-2 & 130.29 & 27.23 & 125.05 & 193.59 & 103.14 \\
Local & 133.21 & 134.30 & 167.17 & 141.88 & 157.07 \\
Mean & 133.19 & 45.29 & 128.58 & \\
\hline
\end{tabular}

F-LSD $(\mathrm{P}=0.05)$

Location $(\mathrm{L})=18.9$

Genotype $(\mathrm{G})=35.3$

$\mathrm{L} \times \mathrm{G}=70.6$ 


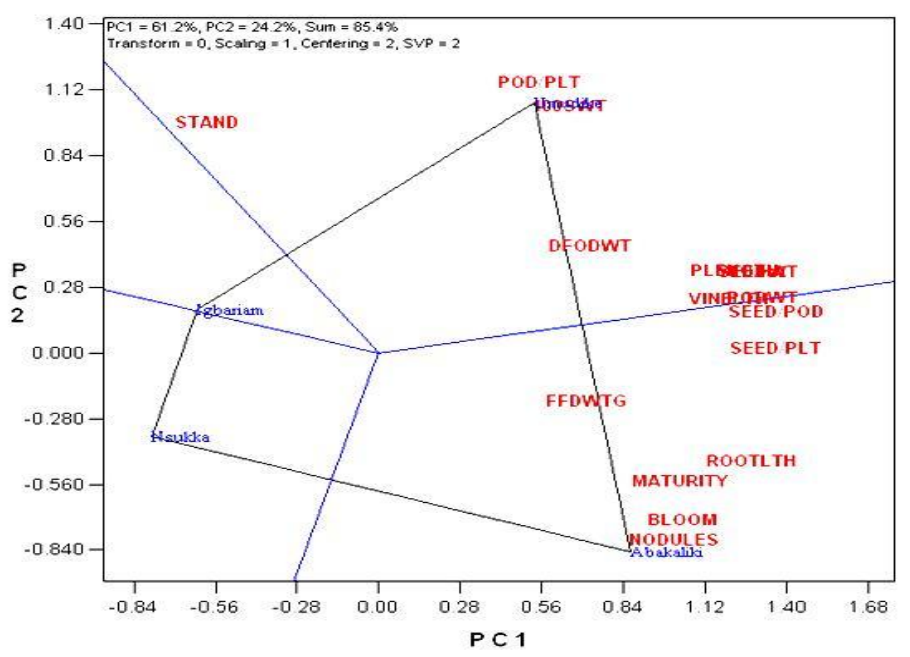

Figure 4: Biplot of location by traits (LT)

$\mathrm{BLOOM}=$ Days to 50 percent flowering; MATURITY $=$ Days to maturity; $100 \mathrm{SWT}=100$ Seed weight; $\mathrm{POD} / \mathrm{PLT}=\mathrm{Number}$ of pods per plant; SEED /POD = Number of seeds per pod; SEED/PLT = Number of seeds per plant; PLENGTH = Pod length; PODWT $=$ Pod weight; SEEDWT $=$ Seed weight $;$ GYLD/HA = Grain yield per hectare; DFWT $=$ Dry fodder weight; FFWTG = Fresh fodder weight; NODULES=Number of nodules; NSTAND=Number of plant stand; ROOTLTH=Root length; VINELTH=Vine length.

Table 4: Effect of location and genotype on grain yield $\left(\mathrm{kg} \mathrm{ha}^{-1}\right)$

\begin{tabular}{lrrrrr}
\hline & \multicolumn{5}{c}{ LOCATION } \\
\cline { 2 - 6 } GENOTYPE & Umudike & Nsukka & Igbariam & Abakaliki & Mean \\
\hline IT 97K-556-4 & 1683.33 & 243.75 & 369.58 & 1228.96 & 881.41 \\
IT 97K-499-35 & 1416.67 & 364.58 & 577.08 & 1180.54 & 884.72 \\
IT 98K-205-8 & 1795.83 & 389.58 & 435.83 & 1192.04 & 953.32 \\
IT 84S-2246-4 & 1450.00 & 418.75 & 489.58 & 1605.37 & 990.93 \\
IT 93K-452-1 & 1033.33 & 83.75 & 619.19 & 1356.92 & 773.30 \\
IT 97K-1069-6 & 1145.83 & 475.00 & 128.33 & 1263.50 & 753.17 \\
IT 90K-76 & 1600.00 & 136.66 & 531.25 & 1228.12 & 874.01 \\
IT 81D-994 & 1150.00 & 191.67 & 246.66 & 1013.08 & 650.35 \\
IT 98K-131-2 & 2250.00 & 450.00 & 637.08 & 1497.54 & 1208.66 \\
IT 90K-82-2 & 1805.41 & 414.58 & 540.83 & 1159.54 & 980.09 \\
IT 90K-568-1 & 1783.33 & 468.75 & 399.58 & 1222.67 & 968.58 \\
IT 89KD-288 & 381.25 & 247.92 & 93.00 & 814.37 & 384.14 \\
IT 90K-277-2 & 1779.17 & 270.83 & 500.00 & 945.62 & 873.91 \\
Local & 76.66 & 252.91 & 88.00 & 1196.00 & 403.39 \\
Mean & 1382.20 & 314.91 & 404.00 & 1207.45 & \\
\hline F-LSD
\end{tabular}

F-LSD $(\mathrm{P}=0.05)$

Location $(\mathrm{L})=115.5$

Genotype $(\mathrm{G})=216.8$

$\mathrm{L} \times \mathrm{G}=433.6$

The genotypes, IT90K-568-1 and IT90K-277-2 produced significantly higher mean number of pods per plant than the other genotypes while IT89KD-288 and local check produced the lowest mean number of pods per plant (Table 6). Umudike location generally supported significantly higher expression of mean number of pods per plant which is comparable with Igbariam. Meanwhile, mean number of pods per plant were significantly lower in Nsukka and Abakaliki when compared to other locations.

Genotype by environment interaction shows that local cowpea check produced significantly higher mean number of pods per plant in Abakaliki in comparison with other locations. This observation is in line with the significantly higher mean grain yield produced by local in Abakaliki location in Table 4.
Figure 1 showed the performance of genotype by location (GL) for grain yield. The biplot model indicated that locations were labeled with upper case while genotypes were labeled with lower case. The Figure showed the GGE biplot for performance of genotypes in each location (GL) which explained $93.2 \%$ $(84.5 \%+8.7 \%)$ of the variation in grain yield per hectare. It confirmed the result in Table 4 which indicates that variety IT98K-131-2 produced higher mean overall grain yield across the four locations. This is because all the four locations fell within the sector where IT98K-131-2 is the vertex genotype. Umudike location supported the highest mean grain yield while Nsukka supporte $\mathrm{d}$ the lowest mean grain yield. Figure 2 showed the GGE biplot for performance of genotypes in each location (GL) which explained $88 \%(72.1 \%+16.5 \%)$ of the variation 
Ezeaku, I.E., Mbah, B.N. and Baiyeri, K.P

Igbariam followed by Abakaliki, while it produced least in Nsukka. The local genotype gave the highest dry fodder yield in Umudike while IT 97K-1069-6 gave the highest dry fodder yield in Nsukka. This finding is in conformity with Table 2 .

Figure 3 showed the genotype by trait (GT) relationship. The Figure showed that the following genotypes, local, IT89KD-288, IT97K-1069-6, IT 90K-568-1 and IT98K-131-2 were the vertex genotypes, indicating that the five genotypes are highly divergent from each other with respect to the traits studied. Almost all the genotypes fell in the sectors where IT 90K-568-1 and IT98K- 131-2 are the vertex genotypes. No genotypes entirely fell in the sectors where local and IT $89 \mathrm{KD}-288$ are the vertex genotypes indicating that they are uniquely different from other genotypes being the only two photo sensitive long duration genotypes used in the study. Similarly, no trait fell in the sector where local is the vertex genotype revealing that the performance of all the traits in the four locations were below average for local. However, DFODWT, VINELTH, FFDWTG, BLOOM, MATURITY, and NODULES, fell in the sector where IT89KD-288 and IT97K-1069-6 are the vertex genotypes. The 100SWT, SEED/POD and ROOTLTH, fell in the sector where IT90K-5681 is the vertex genotype. POD/PLT, SEED/PLT, POD WT, STAND, and SEEDWT fell in the sector where IT98K-131-2 is the vertex genotype.

This result showed that traits associated with a particular genotype are an indication that the trait produced above average value by the genotype.

The genotype, IT81D-994, IT97K1069-6 and IT89KD-288 possessed the highest
VINELTH. Genotype, IT97K-556-4 had the highest 100SWT and NODULES. Genotype, IT97K-499-35, IT93K-452-1, IT98K-205-8, IT84S-2246-4, IT90K-82-2 are clustered within the sector where IT98K-131-2 is the vertex genotype and traits such as POD/PLT, SEED/PLT, PODWT, SEEDWT and STAND are contained within the sector. This showed that IT98K-131-2 along with the associated genotypes expressed these traits prominently.

Location by traits (LT) relationship is shown in Figure 4. Each of the four locations is labeled in lower case, while sixteen traits were indicated in upper case. There are four sectors with each of the four locations occupying the vertices indicating that the four locations were different from each other. The biplot indicated that Umudike location favored greater productivity of cowpea followed by Abakaliki while Igbariam and Nsukka recorded the least performance. The STAND, POD/PLT, 100SWT, PODWT, DFODWT, PLENGTH, SEEDWT, VINELENGTH, PLENGTH and YLD/HA fell within the sector where Umudike is the vertex location while SEED/POD, SEED/PLT, FFDWT, ROOTLTH, MATURITY, BLOOM and NODULES fell in the sector where Abakaliki is the vertex location. Tables 2-6 also showed that these traits were best expressed in these two locations and therefore explained the variation detected by the LT biplot. No trait fell in the sector where Igbariam and Nsukka were the vertex locations, revealing that none of the 16 traits sampled could manifest its full potentials in the two locations. Moreover, Table 2-6 showed that the two locations (Igbariam and Nsukka) did not support any significant expression of any of the traits except Igbariam location where DFODWT was highly expressed. These results showed that ANOVA and biplot model complements each other. 


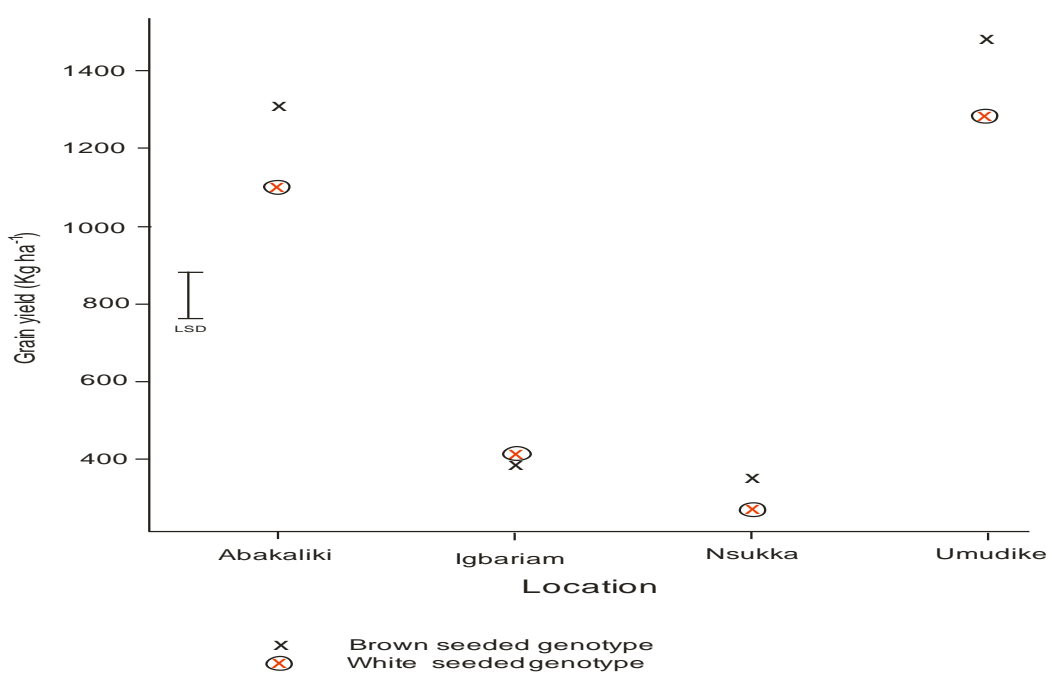

Figure 5: Mean grain yield across four locations at different seed coat color

Table 5: Effect of location and genotype on 100 seed weight (g)

\begin{tabular}{lrrrrr}
\hline & \multicolumn{5}{c}{ LOCATION } \\
\cline { 2 - 6 } GENOTYPE & Umudike & Nsukka & Igbariam & Abakaliki & Mean \\
\hline IT 97K-556-4 & 17.03 & 15.00 & 18.22 & 17.09 & 16.84 \\
IT 97K-499-35 & 15.00 & 14.09 & 16.00 & 14.11 & 14.80 \\
IT 98K-205-8 & 15.14 & 14.37 & 16.00 & 13.43 & 14.63 \\
IT 84S-2246-4 & 12.00 & 12.00 & 13.06 & 13.43 & 12.62 \\
IT 93K-452-1 & 15.69 & 14.00 & 17.17 & 14.00 & 15.37 \\
IT 97K-1069-6 & 14.00 & 15.43 & 16.01 & 15.00 & 15.11 \\
IT 90K-76 & 14.00 & 15.20 & 15.00 & 14.00 & 14.55 \\
IT 81D-994 & 16.44 & 14.04 & 18.40 & 16.39 & 16.32 \\
IT 98K-131-2 & 14.17 & 14.00 & 15.73 & 13.04 & 14.24 \\
IT 90K-82-2 & 10.71 & 12.64 & 13.00 & 13.00 & 12.34 \\
IT 90K-568-1 & 15.00 & 14.18 & 15.87 & 13.67 & 14.68 \\
IT 89KD-288 & 16.06 & 17.30 & 16.01 & 16.00 & 16.34 \\
IT 90K-277-2 & 17.30 & 15.05 & 18.00 & 15.50 & 16.46 \\
Local & 16.00 & 6.00 & 7.59 & 9.34 & 9.73 \\
Mean & 14.90 & 13.81 & 15.43 & 14.16 & \\
\hline
\end{tabular}

F-LSD $(\mathrm{P}=0.05)$

Location $(\mathrm{L})=0.5$

Genotype $(\mathrm{G})=1.0$

$\mathrm{L} \times \mathrm{G}=2.0$

Table 6: Effect of location and genotype on number of pods per plant

\begin{tabular}{|c|c|c|c|c|c|}
\hline \multirow[b]{2}{*}{ GENOTYPE } & \multicolumn{5}{|c|}{ LOCATION } \\
\hline & Umudike & Nsukka & Igbariam & Abakaliki & Mean \\
\hline IT 97K-556-4 & 13.00 & 11.11 & 13.18 & 10.00 & 11.82 \\
\hline IT 97K-499-35 & 22.12 & 9.30 & 20.00 & 8.15 & 14.89 \\
\hline IT 98K-205-8 & 23.41 & 9.00 & 16.67 & 9.11 & 14.55 \\
\hline IT $84 \mathrm{~S}-2246-4$ & 20.00 & 10.00 & 18.90 & 18.09 & 16.75 \\
\hline IT 93K-452-1 & 15.00 & 7.02 & 21.37 & 10.37 & 13.44 \\
\hline IT 97K-1069-6 & 16.22 & 9.49 & 8.14 & 11.00 & 11.21 \\
\hline IT 90K-76 & 14.58 & 10.17 & 14.00 & 11.88 & 12.66 \\
\hline IT 81D-994 & 16.40 & 8.14 & 11.11 & 9.03 & 11.17 \\
\hline IT 98K-131-2 & 22.04 & 10.03 & 19.07 & 13.00 & 16.04 \\
\hline IT 90K-82-2 & 22.35 & 11.00 & 15.55 & 9.00 & 14.48 \\
\hline IT $90 \mathrm{~K}-568-1$ & 23.00 & 14.22 & 20.00 & 14.69 & 17.48 \\
\hline IT 89KD-288 & 8.09 & 10.17 & 9.16 & 6.17 & 8.40 \\
\hline IT $90 \mathrm{~K}-277-2$ & 20.00 & 19.00 & 21.22 & 8.13 & 17.09 \\
\hline Local & 5.01 & 6.45 & 7.00 & 17.00 & 8.87 \\
\hline Mean & 17.23 & 10.36 & 15.38 & 11.12 & \\
\hline
\end{tabular}

F-LSD (P=0.05)

Location $(\mathrm{L})=6.0$

Genotype $(\mathrm{G})=11.2$

$\mathrm{L} \times \mathrm{G}=22.4$ 
The seed coat color of genotypes was analyzed to determine differences in performance across the four locations (Figure 5). There are differences in grain yield between brown and white seeded genotypes with brown seeded genotypes performing generally higher than the white seeded genotypes in all the locations except in Igbariam where white seeded genotypes performed marginally better than brown seeded genotypes.

\section{DISCUSSION}

The results from the combined analysis of variance across the four locations and GGE biplot analysis showed that genotypes, locations and genotype by location component of variation were highly significant for all the traits studied. This result revealed that the genotypes selected for this study were inherently different and they performed differently in the different locations, and that the differential performance could also be explained by variations within each locations and interactions between genotypes and locations. This observation agrees with earlier reports by Singh and Sharma, (1996); Craufurd et al., (1997) that rates of reproductive development, yield and yield components in cowpeas are sensitive to the vagaries of weather and locations. The genotype, IT98K-131-1 demonstrated superiority in performance over other genotypes across the test locations revealing that the genotype has broad adaptation. The genotype IT98K-131-1 as a superior genotype requires large-scale multiplication, promotion and adoption by farmers in south eastern Nigeria. This is the ultimate goal of any crop improvement program which is to develop improved crop varieties, evaluate them in on farm trials and their eventual release for general production. Singh (1993) emphasized that new genotypes must undergo multi-location and macro plot testing before they can be justifiably released as superior varieties. These tests are carried out in order to determine the areas of adaptation and potential use of the test lines as new varieties. The identification of superior lines is based on an assessment of differences among line means and their statistical significance as well as the use of regression analysis to determine the areas of adaptation and yield stability of the test lines (Baiyeri, 1998).

The result also showed that long duration photosensitive genotype, IT89KD-288 and local variety used as check performed poorly in all the locations when compared to the improved early maturing genotypes. This observation is contrary to report by Huxley and Summerfield (1975) that largest yields have been achieved by cowpea crops relatively late to flower or attain maturity. However, our result agrees with the report by Singh et al., (1997) and IITA, (1998) that cowpea improvement program in IITA has led to the development and selection of improved early maturing cowpea lines that combine high harvest index with multiple resistance to pests. On the other hand, local variety and IT89KD-288 produced highest dry fodder yield across the four locations. The two genotypes should be good for use in crop-livestock integration program. This is supported by Tarawali et al., (1997) who noted that most long duration cowpeas produced higher fodders than early to medium genotypes since longer growth period permits greater biomass production.

The very low performance of all the 14 genotypes in Nsukka location could be ascribed to the lower soil $\mathrm{pH}$ in this location and other unfavorable weather conditions during the crops' critical growth phase. Hall (1993); Ismaila and Hall, (1998) noted that high temperatures and relative humidity as well as high soil acidity promotes flower abortion or halt the reproductive phase entirely resulting in low cowpea yield. The low yield could also be attributed to higher pest load in this location since vegetable cowpea is dominant within Nsukka farmers' cropping systems.

Most of the traits that were best expressed in Umudike were reproductive and grain yield components, while the traits best expressed in Abakaliki were mainly growth and reproductive components. These observations could be explained partly on the basis of soil characteristics. The soil textural class in Umudike is sandy loam with high percentage organic carbon (1.2\%) and organic matter $(1.9 \%)$ when compared to other locations. This soil property is most ideal for cowpea grain production. Abakaliki location possesses high soil clay content of $39 \%$, high base saturation of $67.2 \%$ and high cation exchange capacity of $12.5 \%$. These soil physical and chemical properties inherent in Abakaliki location tend to sustain longer soil moisture content in addition to higher available nutrients thus supporting luxuriant vegetative growth of cowpea crop. Warrag and Hall (1983) indicated that when soil moisture content is above optimum at grain filling stage it retards grain formation but enhances vegetative growth.

Our result showed that the highest yielding genotype, IT98K-131-2 was associated with most of the grain yield component. This finding is in agreement with Chauhan et al., (1980); Singh and 
Mehndiratta (1970) who noted that pods per plant and 100-seed weight were the most important characters influencing seed yield in cowpea. Similarly, Afolabi, (1973); Singh et al., (1982), also found that number of pods per plant and ability to fill grain determine seed yield in cowpea. The high grain yield in IT98K-131-2 which we found in association with grain yield components is in agreement with CIAT, (1978). The similarity in the expression of 100-seed weight across the four locations is supported by Uguru and Uzo (1991) who revealed that 100-seed weight in cowpea is less influenced by location because it is genetically controlled.

The observed low grain yield of genotypes possessing high dry and fresh fodder is as expected, given that high fodder production depresses the production of grains as photosyntates are partitioned more to the vegetative parts than the grain parts. This observation is supported by the result of Tarawali et al., (1997). Based on our result, brown seeded cowpea genotypes performed better than white seeded genotypes indicating that brown seeded genotypes are better adapted to southeastern agro-ecology.

\section{REFERENCES}

Afolabi, N.O. (1973). Growth and development of three varieties of cowpea in Western Nigeria. Yield and dry matter production. Tropical Grain Legume Bulletin 20: 3-4.

APS. (2008). Report of the 2007 Agricultural Production Survey (APS). National Food Reserve Agency (NFRA), Federal Ministry of Agriculture and Water Resource, 48-74.

Baiyeri, K. P. (1998). Evaluation of growth, yield and yield components of 36 MUSA genotypes under four different environments. Ph.D. Thesis University of Nigeria, Nsukka, Nigeria 261 pp.

Chauhan, G.S. and Joshi, R.K. (1980). Path Analysis in Cowpea. Tropical Grain Legume Bulletin 20: 5-8.

CIAT (Centro Internacional de Agriculture Tropical) Annual Report. (1978). Bean Program. Pp B1-B85, CIAT, Cali, Colombia.

Craufurd, P.Q., Summerfield, P.Q., Elis, R.H. and Roberts, E.H. (1997). Photoperiod, temperature and growth and development of cowpea. In: Singh, B.B., MohanRaj., D.R., Dashiel, K.E. and Jackai, L.E.N. (eds). Advances in cowpea Research, pp 75-96. Invited paper from the World Cowpea Conference. International
Institute of Tropical Agriculture, Ibadan, Nigeria.

Ezeaku, I.E. (2013). Productivity of grain cowpea (Vigna unguiculata (L.) Walp.) as influenced by season, genotype, insect pest management and cropping system in southeastern Nigeria. Ph.D Thesis, University of Nigeria, Nsukka, Nigeria $290 \mathrm{pp}$.

Hall, A.E. (1993). Physiology and breeding for heat tolerance in cowpea, and comparison with other crops, pp271-280, IN: C.G. Kuo (ed) Adaptation of Food Crops to Temperature and Water stress, Publ. No. 93-410, Asian Vegetable Research and Development Center, Shanhua, Taiwan.

International Institute of Tropical Agriculture (IITA). (1998). Cowpea-cereals Systems Improvement in Dry Savanna, pp 10-60.

Ismail, A.M, and Hall, A.E. (1998). Positive and negative effects of heat-tolerance genes in cowpea. Crop Science, 38: 381-390.

Ntare, B.R. (1992). Variation in reproductive efficiency and yield of cowpea under high temperature condition in a sahelian environment, Euphytica 59: 27-32.

Quin, F.M. (1997). Introduction. PP. ix-Xv. In: Pandey, R.K., and Ngarm, T. (1985). Agronomic research advances in Asia. In: Cowpea research, production and utilization, S.R. Singh and K.O. Rachie (eds). John Wiley and Sons, Chichester, UK, 299-308.

Singh B.B.; D.R. Mohan Raj.; K.E. Dashiell and L.E.N. Jackai (eds.). (1997). Advances in cowpea research. Copublication of International Institute of Agriculture (IITA) and Japan International Research Center for Agricultural Sciences (JIRCAS). IITA, Ibadan, Nigeria.

Singh, B.B. and Sharma, B. (1996). Restructuring cowpea for higher yield. Indian Journal of Genetics 56: 389-405.

Singh, R.; Joshi, B.S. and Singh S. (1982). Correlation studies in cowpea (Vigna unguiculata (L.) Walp) In: Tropical Grain Legumes Bulletin 26: 3-4.

Singh, K.B. and Mehndiratta, P.D. (1970). Path analysis and selection indices in cowpea. Indian Journal of Genetics 30: 417-475.

Singh, B.B. (1993). Cowpea breeding. Pages 1053 in Archival report (1988-1992) of Grain Legume Improvement Programme. IITA, Ibadan, Nigeria. 
Summerfield, R.J., Pate, J.S., Roberts, E.H. and Wien, H.C. (1985). The Physiology of cowpea. In: Singh, S.R. and K.O. Rachie (eds) pp. 101. Cowpea Research, Production and Utilization. John Wiley and Sons LTD. New York NY.

Summerfield, R.J. (1975). Effects of day lengths and day-night temperatures on cowpeas and soyabeans. Proceedings of a Physiology Program Formulation Workshop, Ibadan, Nigeria, IITA, 11-14.

Suzanne, N. and Singh, B.B. (1987). Evaluation of improved breeding lines for quality characters In: Grain legumes improvement. Annual Report pp. 16-17.
Tarawali, S.A.; B.B. Singh.; M. Peters and S.F. Blade. (1997). Cowpea haulms as fodder pages 313-325 in Advances in Cowpea research, edited by B.B. Singh, D.R. Mohan Raj, K.E. Dashiell, and L.E.N. Jackai. Copublication of International Institute of Tropical Agriculture (IITA) and Japan International Research Center for Agricultural Sciences (JIRCAS). IITA, Ibadan, Nigeria.

Uguru, M. I. and J. O. Uzo. (1991). Segregation pattern of decumbent, climbing and bushy growth habits in Vigna unguiculata $(L)$ Walp. Plant Breeding 107:173-176.

Warrag, M.O.A. and Hall, A.E. (1983). Reproductive responses of cowpea to heat at flowering. Crop Science. 23: 56. 